\title{
Exploring how Early School Dropouts Cope as Survivalist Entrepreneurs: A Case Study
}

\author{
Dr Thulani E. Mhlongo, PhD \\ University of Johannesburg \\ South African Council of educators \\ South Africa
}

\begin{abstract}
This article reports on the findings of a research project that was designed to explore how early school leavers cope as survivalist entrepreneurs. The project had four purposes, namely: to determine demographics of this group; to find out how are they able to survive; to get some insight into what they used to do before and to determine variation among vendors in their experiences of street vending. 20 participants were selected randomly. Qualitative Data was collected using interview, observation and reflective notes. Thereafter, data was analyzed using open coding. All participants were school drop-out boys who did not complete their secondary school education. Consequently, they lack specialized knowledge and skills on how to grow their business. About $70 \%$ were immigrants from neighboring countries. Surprisingly, these are able to support themselves and survive as street sellers. The biggest challenge identified by this particular group was weather conditions and harassment by law officials. To improve their working conditions it is up to local municipality to develop rationale policies for understanding the poor street vendors by treating them as part of the broader structural policies aimed at improving their standard of living.
\end{abstract}

Keywords: Survivalist entrepreneurs; school drop-outs; cope, street vending

\section{Background and rationale}

The informal economy in South Africa officially provides employment, as paid work, for $12 \%$ of the labour force. The actual income generated from these survivalists entrepreneurs usually fall short of even a minimum standard of income, with little capital investment, virtually no skills training and only constrained opportunities for expansion into more viable businesses. This is a problem because oppressive by- laws force both women and men into invisible insecure locations where they are potentially exposed to violence, harassment and sexual exploitation. Unfortunately, they cannot stop as they wish because of the families they have to work for. The study of survivalist entrepreneurs is increasingly becoming important in the $21^{\text {st }}$ Century as there is an influx of people into the informal sector particularly those considered as street hawking. In South Africa some city level policies have de-regulated street trading, recognizing its role in local economic development (Statistics South Africa, 2009).

The problem that is to be examined is the experiences and challenges of young survivalists' entrepreneurs.' Generally, poverty and desperate attempts to survive are the prime defining features of street sellers. The situation is that survivalists' enterprises are considered as business of the poor (community of the poor). Engagement of street sellers as an entrepreneur is thought to be necessity driven because they have no choice and their purpose is to feed themselves (means of survival).Although there has been much research on the growth of informal economy, with emphasis on the informal economy in general and also on women street seller, there is a dire need for a more generalized study for both men and women. Nowadays, the phenomenon of "early school dropouts" which is made worse by the problem of "vulnerable street kids" as young entrepreneurs is worth investigating.

\section{Problem Statement}

For many millions of people, particularly poor black South Africans who form part of the informal sector as survivalist entrepreneurs experience hard times and their way of living is not easy as they have to be satisfied with whatever amount they are able to make after a long day's work. For them there is simple no visible alternatives. They have to work for whatever amount they can get or risk starving themselves including their families. 
Generally, Street trading is an income-generating activity where individuals sell their wares along street and sidewalks to passing pedestrians and motorists. Also referred to as hawking, street vendors are generally defined as informal traders who sell goods or services outside of any enclosed premise or covered workspace. Street vending provides employment and incomes to a significant percentage of people who make a contribution to urban life through providing goods and services and by generating employment (Muiruri, 2010: 1).

Street vending can be anything from a survival strategy to a desperate search for a subsistence income to petty capitalism (Street vendors are found in virtually all the major cities of the developing and developed worlds), or the diversification of big business to boost demand and achieve a higher turnover. The income distribution of street vendors is highly skewed, with a few making quite high incomes, comparable to those of successful storekeepers and a career professionals, and most making relatively low incomes, comparable to those of unskilled manual laborers (Bromely, 2000:3).

Most street operations, especially those managed by early school leavers, are much smaller than fixed stores or supermarkets in off-street locations, but a few are quite substantial, ranging from truck-borne mobile stores, to big fixed stalls and kiosks in strategies high demand locations. Bromley (2000: 4) indicates that when street vendors are heavily concentrated in a given street, that street market acquires many of the characteristics of market place, and it may be called a "street market". Nevertheless, most market trading takes place off-street, in public or privately-owned market buildings or marketplaces, or in a parking lots and other open off-street areas temporarily used for artisan fairs, flea markets, swap meets, farmers' markets and other commercial gatherings.

\section{Research questions}

The burning question is how early school leavers cope as survivalist entrepreneurs? In order to answer this question the project had to pursue these sub-questions:

- What are the demographics of this particular group in terms of age, race, and level of education and place of origin?

- How are they able to survive regarding means of living and living conditions?

- Regarding the historical background, do they have any capital to start a business or have they been employed before and how often have they been employed and have they ever had a stable job?

- What are the variations among young vendors in their experiences?

\section{Purpose of the article}

The purpose of this article is to report on the findings of an exploratory qualitative research project that was conducted to investigate how early school leavers around La Rouchellecope as survivalist entrepreneurs on daily basis.

In order to achieve this aim, the project had to pursue these sub- goals:

- To determine the demographics of this particular group in terms of age, race, level of education and place of origin.

- To find out how early school dropouts are able to survive regarding means of survival and living conditions;

- To get some insight into what they used to do before regarding employment history, how often have they been employed and have they ever had a stable job; and

- To determine variations among young vendors in their experiences of street vending.

\section{Significance of the report}

All members of the community (residents, the police, courts and correctional systems) who may be unaware of the seriousness of these experiences can benefit from this report. This will also help those survivalists who are not really aware of what their future chances are for exit or enhancement. Researchers will be enlightened about the fact that the influx of people into survivalist entrepreneurship is still a global problem and still needs further investigation at various levels.

The report will prompt state officials to do self-assessment to determine whether they have successfully played their role in poverty eradication through job creation, if not what else is there for them to do. 
The health problems caused by young street sellers to the urban space and the resultant conflicts with municipal authorities prompts government officials to take appropriate action in this regard (Asiedu\& Agyei-Mensah, 2008: 191).

\section{Literature review}

Street vending can be anything from a survival strategy to a desperate search for a subsistence income to petty capitalism, or the diversification of big business to boost demand and achieve a higher turnover. Most street operations are much smaller in scale than fixed stores or supermarkets in off-street locations, but a few are quite substantial, ranging from truck-borne mobile stores, to big fixed stalls and kiosks in strategic high-demand locations. The income distribution of street vendors is highly skewed, with a few making quite high incomes, comparable to those of successful storekeepers and career professionals, and most making relatively low incomes, comparable to those of unskilled manual labourers (Bromley, 2000: 3)

Bromley (200: 4) indicates that when street vendors are heavily concentrated in a given street, that street acquires many of the characteristics of a market place, and it may be called a "street market". Nevertheless, most market trading takes place off-street, in public or privately-owned market buildings or market places, or in parking lots and other open off-street areas temporarily used for artisan fairs, flea markets, swap meets, farmers' markets and other commercial gatherings.

According to Brink, Cant and Ligthelm (2003: 1) it is estimated that the failure rate of small, medium and micro enterprises is between $70 \%$ and $80 \%$ while millions of rand are being lost on business venture because of essentially avoidable mistakes and problems. It is argued that the ideas are good and the people behind them are competent, but "they do not have a clue of how to run a business" and have no underlying appreciation of business fundamentals. Other problems range from environmental to financial or managerial in nature; lack of appropriate business permits; violation of zoning codes; failure to report tax liability; non-compliance with labour regulations governing contracts and working conditions and/or the lack of legal guarantees in relations with suppliers and clients (Cross, 2000: 37). Some street vending takes advantage of public space and this is in fact where most of the struggle lies, it minimizes overhead costs of rent and utilities and it is ideally suited for informal growth, to the extent that it can withstand hostile attempts to over-regulate or eliminate it, either through evasion, negotiation, or conflict, thus these reasons give rise to different opinions/argument.

\section{Argument in favors and against street vending}

There is no clear, simple and absolute way of determining which set of arguments is correct. Both sets are correct to some degree, and it is possible to mix the two sets, arguing that some types and locations of street vending are desirable while others are undesirable. The arguments for and against street vending have obvious class and ideological dimensions (Bromley, 2000: 10).Bromley (2000: 11) further elaborates that street vending can be portrayed as a vivid example of grass-roots entrepreneurship, individualism and the exercise of civil liberties, and the attempts to suppress, regulate or control street vending may be viewed as authoritarianism, statism, censorship, or the protection of oligopolies established by off-street traders.

Similarly, those who adopt a populist, democratic socialist perspective focusing heavily on the needs, rights and potentials of ordinary people, tend to advocate for street vending because of the income opportunities it provides. Many of the arguments against street vending are then dismissed as "blaming the victim" - criticizing the poor when the socio-economic system is characterized by gross inequality and exploitation. Much of the research on the informal economy based on Valodia, Lebani and Skinner (2005: 26) has concentrated on explaining the growth of the informal economy. From an employment policy perspective there is an urgent need for research aimed at identifying areas for growth in informal employment/experiences of survivalists' entrepreneurs and the policies needed to realize this potential. The reality is that most of these people are illiterate and have no skills to fill any of the existing vacancies in South Africa.

\section{Working Conditions}

According to Brink, Cant and Ligthmelm (2003: 1) it is estimated that the failure rate of small, medium and micro enterprises between $70 \%$ and $80 \%$ while millions of rand are being lost on business venture because of essential avoidable mistakes and problems. 
Common problems include, among others, unsafe and polluted environmental conditions in which informal businesses take place; financial problems(they live from hand to mouth)and managerial problems(young entrepreneurs do not have a clue on how to run a business and in most instances they have no underlying appreciation of business fundamentals). Muiruri (2010: 10) estimated that in all countries where data is available, informal traders' mainly street vendors represent a very high proportion (73\% - 79\%) of employment in trade and a significant share (50\% -90\%) of trade gross domestic product (Brink et al., 2003: 1). Because the conditions under which street vendors operate are often undesirable for both the preparation and the selling of porters, vegetables, fruits, bread, pastries, cooked food and modern and traditional medicines, including soap, cigarettes, pens, pencils, note books, clothing, razor blades, and knives etc, thus these vendors are faced with numerous difficulties. Vending stalls are, for example, usually located outdoors, with or without roof cover, and situated in high pedestrian traffic areas (such as on pavements at taxi ranks, bus stations, train stations, building construction sites, school premises and hospitals). The majority of these vending sites furthermore lack basic infrastructure and services such as potable running water and waste disposal facilities, hand and dishwashing water is usually insufficient and often reused, sometimes without soap, waste water is discarded in the street and garbage often disposed of in the vicinity of the stall (Lues, Rasephei, Venter \&Theron, 2006: 2). In the majority of cases street vending is an individually-owned business, vendors are not accountable to supervisors, so the reporting of illness is irrelevant. Assessment of the structures of the vending sites revealed $38 \%$ of them being regarded as "poor" (without any form of structure), 60\% as "fair" (without some kind of informal structure) and only 2\% as good (a permanent or semi-permanent structure) (Lues et al., 2006: 9). Street vendors are more exposed to environmental hazards and are predominantly from much weaker socio-economic backgrounds and yet cater to the general mass.

\section{Global perspective}

The history of street traders in Kenya dates back to many years. Until the early 1990s street trading was largely the main domain. However, this changed as more women have joined the trade, giving a new face by using a different approach where they station themselves at strategic points such as near supermarkets, restaurants, street and other outlets with large human traffic. These markets specialize with fresh vegetables and fruits and to maximize sales, the women conduct business from late afternoon when city residents leave their offices for the journey home (Muiruri, 2010:2). Street vendors` problems have slightly changed over time, yet their role in the economy is evolving with new products and expanding opportunities. They are gaining recognition as being important in urban development and they will not disappear any time soon. Street vendors are without any rights and are instead treated as nuisance. Despite the importance of the street vendors, their participation and obstacles they face are less understood and less recognized. This has resulted in lack of enabling policies, regulation and organization of the sector (Muiruri, 2010: 2).

Insensitivity of urban policy makers in their perception of street trading as an illegal activity denies street vendors a right to decent work and it is necessary to correct the public policy bias and establish their right of recognition as an integral part of the urban distribution system (Muiruri, 2010: 3). Thus these perceptions of policy makers on street vendors give rise to particular arguments both in favour of and against street vending/hawking. In the light of the preceding argument, the arguments for and against street vending have obvious class and ideological dimensions which are briefly summarized below:

\section{Arguments against Street Vending}

The arguments against are often more specific and trivial than those in favour, for example, the citizen's constitutional right to freedom of trade and entrepreneurship, for example, seems to be a more weighty consideration than the fact that other citizens may be disturbed or irritated by street vendors' commercial solicitations (Bromley, 2000: 6). Street vendors are not evenly spread across the city. In order to maximize their sales, they concentrate very heavily in a few locations where there are pedestrian and vehicular congestion. Thus, they impede the flow of traffic and as such they are viewed as indirect causes of traffic accidents as well as increased levels of vehicle-generated air pollution. Crowded sidewalks, vendors in the roadway, and pedestrians displaced onto the roadway may block motorists' sight-lines at intersections, and the lively activity of street sales may distract motorists from the driving (Bromley, 2000: 7).

Pedestrianizing streets creates additional space for street vendors and pedestrians, and it may be very effective in reducing street noise and pollution levels, but it reduces the number of routes available to motor vehicles; it impedes door-to-door deliveries and collections and it may create access problems for emergency vehicles. 
Street vendors may block the routes of egress from crowded buildings like theaters, stadiums and department stores, increasing the scale of the tragedy in the event of a major fire, explosion, toxic gas escape or mass hysteria (Bromley, 2000: 7).

Street vendors can and often do "forestall" off-street businesses, attracting potential purchasers as they walk into a concentration. Bromley (2000: 11) further elaborates that street vending can be portrayed as a vivid example of grass-roots entrepreneurship, individualism and the exercise of civil liberties, and the attempts to suppress, regulate or control street vending may be viewed as authoritarianism, statism, censorship, or the protection of oligopolies established by off-street traders. Similarly, those who adopt a populist, democratic socialist perspective focusing heavily on the needs, rights and potentials of ordinary people, tend to advocate for street vending are then dismissed as "blaming the victim"- criticizing the poor when the socioeconomic system is characterized by gross inequality and exploitation.

\section{Types of street vendors}

There are two types of vendors which have been identified by Asiedu \& Agyei-Mensah (2008: 193), the first one being the walking vendors and the second one fixed vendors. Walking vendors include porters, and sellers of vegetables, fruits, bread, pastries, cooked food and modern and traditional medicines. They also include vendors who sell different kinds of manufactured goods such as soap, cigarettes, pens, pencils, note books, clothing, razor blades, and knives. Fixed vendors, on the other hand are those who remain in particular locations repairing batteries and tires, barbering, selling cooked foods, and operating small shops and kiosks. Most of the vendors locate themselves in strategic, easy to be seen spots that attract heavy human and vehicular traffic. These spots are usually found in/along major roads and streets, near markets, shopping centre and public offices. Street vendors occupy these locations without official permission, usually employing informal methods such as consultations with the owners of neighborhood facilities or negotiating with acquaintances or people who have already been allocated spaces by local authorities, or they share spaces with relatives, friends and colleagues.

The fact is that most urban authorities have no consistent policies and regulations applying to street vendors and continue to view their activities as a nuisance, a menace and an eyesore. Hence, vendors are exposed to conflicts of varied forms and nature. Conflicts may arise among themselves, with urban authorities, with formal traders, and with general public over contestations and conflicts concerning the use of urban space, especially in terms of the inconveniences faced by pedestrian and vehicular traffic as a result of blocked streets, the health risks posed by roadside food vendors, and the generation of excessive amounts of garbage (Asiedu et al., 2008: 193).

\section{Categorizing Street vending or hawking}

Street vending usually falls within the category of informal economic activity. This category includes "the production and exchange of legal goods and services that involves the lack of appropriate business permits, violation of zoning codes, failure to report tax liability, non-compliance with labor regulations governing contracts and working conditions, and/or the lack of legal guarantees in relations with suppliers and clients" (Cross, 2000: 37). Since, street vending takes advantage of public space-and this is in fact where most of the struggle lies, it minimizes overhead costs of rent and utilities and it is ideally suited for informal growth, to the extent that it can withstand hostile attempts to over-regulate or eliminate it, either through evasion, negotiation, or conflict.

Despite the huge popularity of street vending activities within the range of informal sector activities, Bromley (1988) in Asiedu et al. (2008: 191) have reported that there is a lack of research and accurate data on the subject and have intimidated that there has been research bias against it, while other informal activities such as production and manufacturing activities have received more research attention.

Asiedu et al. (2008) and Valodia, Lebani and Skinner (2005: 26) believes that much of the research on the informal economy has concentrated on explaining the growth of the informal economy not particularly on street vending. From an employment policy perspective there is an urgent need for research aimed at identifying areas for growth in informal employment/experiences of survivalist's entrepreneurs and the policies needed to realize this potential. Asiedu et al. (2008: 191) has acknowledged the neglect of the spatial dimension of street vending activities, going a step further Asiedu et al. indicate that research on the sector has been particularly challenging due to the itinerant nature of vendors, whose businesses tend to expand, become bankrupt and vanish overnight. According to Cross (2000: 43), it should be kept in mind that a good part of the problem lies not in the phenomenon occurring in their streets, but in their preconceived notions of the "appropriate" use of public space. 
Street stall get in the way of traffic precisely because city planners have left them with no other viable place to go. The reality is that most of these people are illiterate and have no skills to take any of the half a million vacancies in South Africa and this is mostly the case for most women, but keeping in mind that there is also certain percentage of men who are also in the same situation or who are also affected.

\section{Gender differences in street vending/hawking}

Based on one of the objectives, thus wanting to determine the gender (biographical information), Asiedu et al. (2008: 193) believe that due to limited economic opportunities, which in turn are primarily due to gender bias in education, women dominate the informal sector, as it offers the flexibility in combining their activities with other household related ones, particularly taking care of children. Men on the other hand, have been noted to join the street trade, but leave while they are still young for other jobs in contrast women join the trade later in life and continue until old age.

Furthermore, men are known to invest in more capital intensive and high profit yielding businesses than women. Street vendors constitute a significant share of total employment in the informal sector and street vending units constitute a significant share of total enterprises in the informal sector. Women account for more than 50\% and up to $90 \%$ of informal employment in trade, except in those countries (such as Tunisia and India) where social norms restrict women's mobility outside the home (Chen, 2001: 4).

\section{Legalizing Street vending (hawking)}

Bhowmik (2003: 1545) states that one of the ways of legalizing street vendors is by issuing licenses to them. The municipal authorities are thus able to keep a check on the number of vendors and can also earn revenue through license fees and other charges. Legalizing of street vending and eviction by the concerned authorities provided this system is more liberal. Unlicensed street vendors are vulnerable to all sorts of extortion from various quarters. The police and municipal authorities extract rents for allowing them to operate. Studies on street vendors indicate that around 20 per cent of the meager earnings of these people are paid as rents. According to Bhowmik (2003: 1545), the underworld too steps in many places, ostensibly to provide 'protection'. Vendors become victims of these corrupt practices and also depend on them for the survival. Another aspect connected with legalization is eviction. Besides causing financial hardship and impoverishment, eviction leads to loss of dignity for the vendor. The policy lays down that evictions should be avoided but where relocation of street vendors is necessary, a minimum notice of 30 days should be served to them. It further notes that vendors or their representatives should be involved in the planning and implementing of relocation and efforts have to be made to ensure that vendors in the new locality have the same earnings as the pre-evicted level (Bhowmik, 2003: 1545).

\section{Solution to the problem of street vendors (street trading)}

It is up to local government to develop rational policies for understanding vendors by making them part of the broader structural policies aimed at improving their standard of living by giving them legal status, issuing licenses and providing appropriate hawking zone in urban areas. It is therefore significant to assist decision-makers to formulate appropriate policies through the participation of street vendors. Cross (2000: 45) indicates that another way of solving the problem of street trading/vending is to create a specific geographic areas and/or economic sectors in which small, low capital, individual or family-run firms are allowed to operate under a self-regulating system with tax and regulatory enforcement reduced to the bare minimum.

The fact is that no plan for improving the city can be successful without the participation of the urban poor. They need to be integrated into the planning process and in campaigns for a better environment. The involvement of street vendors in keeping the pavements clean could be very beneficial for the urban population. But this cannot be done if hawking is regarded as illegal. If hawking is legalized and regulated, street vendors could be given the responsibility of keeping their environment clean. This would be readily accepted by them as no hawker likes to work in unclean surroundings (Bhowmik, 2003: 1546).

In other words, it is also beneficial to recognize a system of semi-formality on the level of entire low-income neighborhoods, focusing on goods and services that can be provided by micro-enterprises. Furthermore the solution can be to take advantage of the postmodern emphasis on the multiple layers of reality. Rather than lowering the formal system to the level of the informal sector, or raising the informal sector to the level of the formal sector, as many development projects focusing on the micro-business sector seem to attempt, the suggestion is that policy makers should create ways in which formal and informal sectors can exist side-to-side (Cross 2000: 47). 
Street vendors are mainly those people who are unsuccessful or who are unable to get regular jobs. The study on the street vendors showed that the lower income groups spend a higher proportion of their income in making purchases from the street vendors mainly because their goods are cheap and affordable. Had there been no street vendors in the cities the plight of the urban poor would be worse than what it is at present. Street vendors helps another section to survive, hence though street vendors are viewed as a problem for urban governance, they are in fact the solution to some of the problems of the urban poor. By providing cheaper commodities street vendors are in effect by proving subsidy to the urban poor, something that the government should have done (Bhowmik, 2003: 1543).

Lues et al. (2006:2) believe that local government should intervene to ensure that the standard of safety of street foods and other forms of street selling/hawkers are best attainable under the circumstances of any prevailing situation. This could be accomplished by relevant authorities playing a role in providing the vendors with training and seminars on any of the above mentioned form of street selling or vending. Such training should preferably be made available to the street food vendors and other vendors free of charge. Support from local authorities in the form of adequate infrastructure with services such as water supply, toilets, refuse disposal and waste water disposal facilities, is also needed. It is also important to identify or determining what the nature and effectiveness of coping strategies adopted by vendors to overcome the coercion that they face from various sources and what solutions have been proposed by the planners and urban authorities to the problem of street vending if however, it is a problem.

\section{Research design and methodology}

The researchers used a case study which was an appropriate design for the exploratory research project. In an effort to get an in-depth understanding regarding how early school leavers cope as survivalist entrepreneurs, a qualitative research paradigm was employed in a natural setting. This approach is supported by Flick (2007: 3)who argues that qualitative research paradigm claims to describe life-worlds "from the inside out" from the point of view of the participants in the research project.

\section{Target population and the chosen sample}

The target population of the research project was20 boys aged between the ages of 14 and 17 who operated as street sellers in the streets of La Rouchelle Central Business Centre. There were no female vendors between the ages of 14 and 17 in La Rouchelle CBD at the time of the research project. Since there was no list on street sellers, non-probability sampling was used as a convenient sampling method because the participants who were interviewed were those 20 boys who were available at the/that time. In this context probability sampling would not be appropriate. Although the study was conducted in the La Rouchelle CBD area it was, however, spread across the area.

\section{Data collection and analysis}

Data was collected by means of interview interlinked with observation techniques and reflective notes. Qualitatively derived data was analyzed through open coding. The information was then interpreted and compiled into a research report.

\section{Ethical issues}

In order to strengthen the trustworthiness of the research project, no participant was coerced to be part of this study. Respect and trust were achieved largely through assuring all participants of the confidentiality of the information they gave. The questionnaire did not require any identification of region, school or person to be filled in (Neuman, 2003:126). Participants were assured that the information gathered would not be used for personal gain, as that would amount to exploitation of the respondents' innocence. Through the covering letter the respondents were also reassured, through the letter, of the confidentiality of the information they provided. Privacy and trust was maintained by holding closed door interviews (inside the cars) and there was no disclosure of information to any other person except people involved in the study (Neuman, 2003:126). All the participants participated voluntarily.

\section{Trustworthiness of the report}

This report adhered to Maree (2010:80) suggestion by engaging multiple methods of data collection such as observations, interviews and document analysis which led to trustworthiness. In addition, involving several investigators and peer researchers to assist with the interpretation of the data also enhance trustworthiness. 
To test the extent to which the study measured whatever it was measuring consistently (Best \& Kahn, 2003:285); categories of the frequently occurring data were identified and checked. Since the main issue of reliability is dependability (Neuman, 2003:184), data was established by capturing all interviews on a tape recorder and transcribed in writing. During the transcription exercise, only parts of the respondent's story that were not commensurate with the research topic and had no significance to the research were eliminated. Attempts were made to reproduce the interview scripts as accurately as possible. The interviews were unbiased and care was taken not to ask leading questions or to be over-impressionistic in observations.

\section{Limitations of the research project}

There were only two field workers. Consequently, the population size had to be limited to only twenty participants. Time constraint was also a limitation including the fact that the findings cannot be generalized to all the vendors in the whole of Johannesburg due to the limited sample size.

\section{Findings and discussions}

Early school leavers as survivalist entrepreneurs form part of major components of the South African informal economy. This section presents the findings which are basically based on the experiences of the young survivalist entrepreneurs around La Rouchelle (South of Johannesburg). The significance of these findings is that they do not only provide recommendations but they also indicate areas for future research. Literature review revealed that men account for more than $90 \%$ and up to $50 \%$ of informal employment in trade, except in countries such as Tunisia and India where social norms restricts women's mobility outside the home (Chen, 2001: 4). The research project was not based o the quantity of participants but it was based on how 'early school dropouts cope as survivalist entrepreneurs. Thus, this report presents what was revealed by the findings of that project. Findings revealed that in the area of La Rouchelle there were no female street vendors below the age of 17 when the research project was conducted. The reason for this might be the fact that most females between the ages of 13 and 17become actively involved in sexual activities and they fall pregnant and thus, for the safety of their babies the social workers and some NGO's remove them from the streets for safety of their babies. Only 20 boys between the ages of 14 and 17 were singled out as survivalist entrepreneurs. Their biographical information is shown in Table 1 below.

Table 1: Age of the participants

\begin{tabular}{|l|l|l|}
\hline AGE & NUMBER & \% \\
\hline 14 & 1 & $5 \%$ \\
\hline 15 & 1 & $5 \%$ \\
\hline 16 & 5 & $25 \%$ \\
\hline 17 & 13 & $65 \%$ \\
\hline Total & 20 & $100 \%$ \\
\hline
\end{tabular}

The majority of them aged $17(65 \%) ; 5$ of them aged $15(25 \%)$; only one aged $17(5 \%)$ and one aged $14(5 \%)$. Coming to the question of employment on the street, all of them are seriously looking for odd jobs (especially those between the ages 15 and 18).Since cost of living is high,one can assume that these survivalist entrepreneurs have to pay rentals, leaving them with no alternative options but to enter the vending business as it is the most possible solution for them to survive. At the ages 16,17 and 18 one can also expect some of them to be cohabiting even if they are not formally married. Naturally at these ages these boys are unable to get married because they have no stable jobs and financial muscle to support a wife and a family.

Home languages of the participants

Figure 1: Bargraph represent home language of the participants

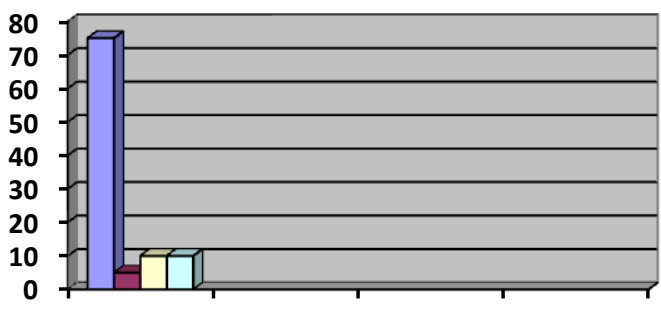

口English
$\square$ Pedi \&Sotho
$\square$ Isizulu
$\square$ Other (French \& Portugees


As indicated in figure 1 above, it was revealed that the majority of vendors were from Mozambique, Maputo, Lesotho and very few of them originated from the local townships. Their home language indicates their place of origin or their ethnic background. As La Rouchelle is snuggled in the heart of the Southern suburbs, which is evidently a white people domain, the majority of the vendors where English speaking (75\%).

The second largest group were Zulu speaking (10\%), followed by French and Portuguese (10\%). Very few people used Pedi and Sotho (5\%). The research findings revealed that the overwhelming majority of the early school leavers who were vending around La Rouchelle were people from Maputo, Mozambique, Zimbabwe, Kwa-Zulu Natal, Lesotho and neighboring townships, but who are now living around La Rouchelle. About 5\% of the young vendors are not permanent residents in the area. $40 \%$ of these boys indicated that they live with their relatives who own homes in the area as they could not even afford to rent rooms. The remaining $25 \%$ live in the backrooms of their landlords but because they cannot afford to pay rentals they work for accommodation during certain days of the week. $15 \%$ of the boys live with their extended family members and only $5 \%$ of them indicated that they are living with their close friends. They reason they came to the La Rochelle area is that they were looking for jobs opportunities because they have to earn a living.

Situation analysis revealed that:

- The majority of survivalist entrepreneurs were male.

- The majority of those who left school at an early age fall into the age category of 14 to 17 .

- Their language of domineer is English for communication purposes.

- The overwhelming majority of survivalist entrepreneurs between ages of 14 to 17 who were vending around La Rouchelle were people from Maputo, Mozambique, Zimbabwe, Kwa-Zulu Natal, Lesotho and Neighboring townships.

\section{Current Working Situation}

This part of the findings focused on the actual working situation of vendors and how they actually experiencing vending in La Rouchelle. The reason for this question was to get a deeper insight into vending, how they are surviving, for example, the duration of working as a vendor, number of days worked, type of transportation and related issues. The responses were as follows: All boys said: "We work hard for long hours daily and we use taxi as a means of transport. We make decisions on what we want to sell, at what price, and so we are able to gain experience regarding small business management."

\section{Constraints that make it difficult to operate}

The first question was the one on city authorities (law enforcement) or their treatment in terms of the vending industry. About $40.4 \%$ of the vendors have been asked to move at one point. There are no stalls in the South of Johannesburg. $36.8 \%$ have not been asked to move and the other $15.8 \%$ added that the authorities, business people, and people around treat them with respect and support. They reported that they do not pay a membership fee unlike other street sellers in other city centres where they pay monthly municipality membership fee to the "Committee for Hawkers"as a form of security or protection fee. They reported problems regarding to infrastructure including related services provision (water, toilet) and shelter for protection during rainy days. Robbery and theft among them did not emerge as problems for them because $89.5 \%$ indicated that they never experienced them at all. Only $10.5 \%$ said that it happened seldom. Assault was also not a problem. $98 \%$ said that they never experience assault or harassment and only $2 \%$ said that if it does occur it is only seldom.

\section{Personal feelings with regard to daily challenges}

In response to the question why they became vendors $70 \%$ reported that they have to fend for themselves and only $30 \%$ said that they can't afford any other form of employment due to their tender age andlow level of education.

\section{Working history of the participants and conditions of the service}

In response to the question regarding their working history it was evident that more than $99 \%$ have never had stable jobs. Those who had jobs were left unemployed due to retrenchment and company closing down.

\section{Socio-technical skills and level of education}

Since education is a determination factor in employment it was necessary to find out whether low level of education is a determining factor that contributed to. In an individual interview with the participants, $15 \%$ of the participants reported that they never attended school in their entire life. 
$10 \%$ reported that they had quit school in Grade 10 and Grade 12, and majority of them $70 \%$ reported that their main reason being poverty and financial problems. In terms of any additional skills after quitting the school only $5 \%$ reported that they have received training in plastering, and that they could do odd jobs such as bricklaying, painting and gardening.

\section{Basic needs, personal visions and future plans interlinked with financial capital to start own business}

It was necessary to determine whether young street vendors can survive to meet their basic needs. It was found that about $89 \%$ of participants can survive and only $11 \%$ cannot survive. When asked to express their views about their future plans, $100 \%$ were positive about their future. All of them indicated that they want permanent jobsso that they can secure financial loans to start their own businesses. This was a brilliant answer because right now they lack the so-called collateral needed by most financial institutions.

\section{Recommendations}

- It is up to local government to develop rational policies for understanding vendors by treating them as part of the broader structural policies aimed at improving their standard of living.

- It is up to every municipality and province to determine its own by- laws to regulate street trading because the inadequate regulation opens vendors up to all sorts of problems.

- Municipality must also provide information about association for the hawkers, in order to avoid disorganization of the street vendors in the public space.

- Vendors must create a conductive environment to attract customers.

- The fact that street vendors they did not complete secondary schooling, they lack specialized and skills, knowledge on how to run a business. To have a skill to run a business is very important e.g. bookkeeping, records, savings etc. They have to do short courses in bookkeeping, savings, stock taking, drawing a business plan etc.

- There is a dire need for a more generalized study as this study focus on boys only, as there were no female vendors in that locality during the time of the research project.

\section{Conclusion}

Due to gender bias, it is most often claimed that street vending is a business for poor women and girls. Surprisingly, in consistent with the national figures that showed shocking statistical figures of less educated entrepreneurs in the business world, this report found that the majority of the boys who were operating as survivalist entrepreneurs around La Rouchelle CBD were semi-literate. They did not even complete Grade 12. The majority of them were immigrants from Lesotho, Zimbabwe and Mozambique. They decided to operate in the Southern Suburbs where it was not expected of them to pay municipal fees. Based on what they have said they have not yet been subjected to public disapproval, harassment by law official and criminals that usually operate in city centres. However, their main problems are lack of infra-structures for street sellers and unfavorable weather conditions during rainy seasons and severe cold in winter.

\section{References}

Asiedu, A.B. \& Agyei-Mensah, S. (2008). Traders on the run: Activities of Street Vendors in the Accra Metropolitan Area, Ghana. Norsky Geografisk Tidsskrift-Norwegian Journal of Geography Vol. 62, 191 202.

Babbie, E. \& Mouton, J. (2001). The Practice of Social Research. Cape Town: Oxford University Press.

Best, J.W. \& Khan, J.V. 2003. Research in Education. Boston: Pearson Education.

Bhowmik, S.K. (2003). National Policy for Street Vendors: Economic and Political Weekly. Vol. 38 (16), pp 1543 - 1546. Retrieved from http://www.jstor.org/stable/4413453pdf on 06 May 2011.

Brink, A., Cant, M. \& Ligthelm, A. (2003). Problem Experienced by Small Businesses in South Africa: Paper for the Small Enterprise Association of Australia and New Zealand $16^{\text {th }}$ Annual Conference Ballarat. Retrieved from: http://www.cecc.com.au/programs/resource manager/accounts/seaanz papers /Newd ocCant.pdf on 07 May 2011.

Bromley, R. (2000). Street Vending and Public Policy: Global Review: International Journal of Sociology and Social Policy. 20 (2). 1 - 29.

Creswell, J.W. (1994). Research Design: Qualitative and Quantitative Approaches. California: Sage. 
Cross, J.C. (2000). Street Vendors, Modernity and Postmedernity: Conflict and Compromise in the Global Economy: International Journal of Sociology and Social Policy, 20 (1/2). 29 - 52.

Flick, U.( 2007). Managing Quality in Qualitative Research. London: Sage Publication Ltd.

Lues, J.F.R., Rasephei, M.R., Venter, P. \& Theron, M.M. (2006). Assessing Food Safety and Associated Food Handling Practices in Street Food Vending: International Journal of Environmental Health Research, 65 (5), pp 319 - 328. Retrieved from http://wwwdx.doi.org/10.1080/0960312060086914 on 31 May 2011.

Maree, K. 2010. First Steps in Research. Pretoria: Van Schaik.

Muiruri, P. (2010). Women Street Vendors in Nairobi, Kenya: A situational and Policy Analysis within a Human Rights Framework. Ethiopia: Addis Ababa: Organization for Social Science Research in Eastern and Southern Africa.

Neuman, W.L. 2003. Social research methods: Qualitative and quantitative approaches. Boston: Pearson Education.

Statistics South Africa. (2009). Quarterly Labour Force Survey: Quarter 4. Pretoria: Statistic South Africa.

Valodia, I., Lebani, L. \& Skinner, C. (2005). Low Waged and Informal Employment in South Africa: Review of Labour Market in South Africa: Pretoria: Human Science Research Council. 